\title{
Unraveling the Competence Development of Corporate Social Responsibility Leaders: The Importance of Peer Learning, Learning Goal Orientation, and Learning Climate
}

\author{
E. R. Osagie ${ }^{1}$ (i) $\cdot$ R. Wesselink ${ }^{1} \cdot$ P. Runhaar ${ }^{1} \cdot$ M. Mulder $^{1}$
}

Received: 17 March 2016/ Accepted: 5 July 2017/Published online: 14 July 2017

(c) The Author(s) 2017. This article is an open access publication

\begin{abstract}
The implementation of corporate social responsibility (CSR) objectives within companies is often managed by a CSR leader or a small team of CSR leaders. The effectiveness of these CSR leaders depends to a large extent on their competencies. Previous studies have identified the competencies these professionals need, yet it remains unclear how these competencies can be developed. Therefore, the aim of this survey study was to reveal how CSR leaders develop their competencies and to explore which learning activities CSR leaders $(N=176)$ engage in. The results showed that informal learning activities that center on learning with and from peers outside the company are particularly emphasized. In addition, this study examines whether and how dimensions of companies' learning climates (i.e., facilitating, awarding, and erroravoiding learning climates) and CSR leaders' learning goal orientation (LGO) affect the competence of CSR leaders. We found significant interaction effects between the learning climate dimensions. Furthermore, we found an even stronger and positive connection between LGO and CSR competence, highlighting the importance of attracting
\end{abstract}

\author{
E. R. Osagie \\ eghe.osagie@han.nl \\ R. Wesselink \\ renate.wesselink@wur.nl \\ P. Runhaar \\ piety.runhaar@wur.nl \\ M. Mulder \\ martin.mulder@wur.nl
}

1 Chair Group Education and Competence Studies, Social Science Group, Wageningen School of Social Science, Wageningen University, P.O. Box 8130 , 6700 EW Wageningen, The Netherlands
CSR leaders with a strong LGO for driving the CSR implementation process. Moreover, a supportive learning climate further stimulates CSR leaders' engagement in continuous learning, which is necessary for coping with the complexities associated with implementing CSR.

Keywords Corporate social responsibility competence . CSR implementation · CSR leaders · Learning goal orientation $\cdot$ Learning climate

\section{Introduction}

It is commonly acknowledged that a thorough implementation of corporate social responsibility (CSR) in a company's core business processes is essential for dealing effectively and continuously with sustainable development (SD) challenges (cf. Bertels et al. 2010; Jamali 2008). Since leaders can greatly influence employee work behavior and therefore play a crucial role in the implementation process (Furst and Cable 2008), scholars increasingly focus on the role of CSR leadership (e.g., Cramer 2003; Huang 2013). In most studies, the role and support of the CEO takes center stage (e.g., Huang 2013; Mazutis 2013), while it is usually others within the company who actually drive and lead the CSR implementation process. Therefore, Waldman and his colleagues (2006) call for more research on CSR leadership at the different company levels. The current study addresses this call by focusing on those professionals that bear the responsibility of leading the CSR implementation and who are referred here to as: "CSR leaders." In particular, we examine the individual competence (development) of these CSR leaders. Individual competence refers to a complex set of performance-oriented knowledge elements, skills, and 
attitudes needed to achieve specific objectives (Mulder 2014).

Because the job of CSR leader is still in its infancy (Wijdoogen 2016), many CSR leaders are recruited and selected from within the company and occupy a somewhat specific position within it. Unlike many other functional managers, CSR leaders must deal with many uncertainties and must work extensively with external stakeholders due to the wicked nature of SD challenges (Dentoni et al. 2012). Moreover, these professionals must work in environments where there is little support for CSR available or where employees are ambivalent toward the proposed changes. For example, because the beneficial effects of CSR to the company are often not immediately observable (Heiskanen et al. 2015; Hutjens et al. 2015; Wijdoogen 2016).

It is important for companies and (newly appointed) CSR leaders to know which individual CSR-related competencies (CSRCs) CSR leaders need in order to perform their jobs and how said individual CSRCs are acquired and maintained. This will ensure that the right person is selected and that (s)he has or develops, if necessary, the appropriate competencies to adequately lead the CSR implementation process (Willard et al. 2010; Heiskanen et al. 2015). The question as to which individual CSRrelated competencies (CSRCs) CSR leaders need to perform their jobs has been answered in previous studies (e.g., balancing CSR objectives and commercial objectives; see Nijhof et al. 2005, Osagie et al. 2016a, b; Rieckmann 2012; Willard et al. 2010;). However, the question as to how said individual CSRCs are acquired and maintained remains to be answered. Hence, the present study sets out to explore the following two research questions: (1) How are CSR leaders' competencies affected by contextual and personal work-related factors? and (2) Which learning activities are employed by CSR leaders for developing their competencies?

The workplace is often the only place where CSR leaders can develop their competencies. SD challenges are extremely complex, as they are ever-changing, often illdefined, and require multi-stakeholder alliances to tackle them. Making strategic decisions on the basis of such complexities can be challenging (Dentoni et al. 2012) and require competencies that cannot be adequately learned from textbooks but should be developed through workrelated learning. Work-related learning is defined as the employees' participation in the learning activities through which their competencies are developed and which change their current and future achievements and performance (Kyndt and Baert 2013).

Using Billett's $(2001,2004)$ framework on work-related learning - which postulates that competence development at work is influenced by both personal and contextual factors-the present study explores the influence of two key factors, namely the contextual factor, "learning climate" and the personal factor "learning goal orientation" (LGO) (cf. Bock et al. 2005; Chen and Lin 2004; Grossman and Salas 2011; Kyndt and Baert 2013; Noordzij et al. 2013; Tynjälä 2008). Learning climate refers to someone's perception of the extent to which the workplace facilitates learning opportunities and rewards and supports their learning behavior (cf. Nikolova et al. 2014a, b). Such support is essential for learning, as it stimulates employees to experiment and learn new competencies (Tynjälä 2008). $L G O$ refers to an individual's behavior and motivation to improve their competencies through active exploration of, and engagement in, learning activities (Dweck and Leggett 1988; VandeWalle 2001). LGO has been associated with increased learning from failure, which is an important way of gaining new competencies (Noordzij et al. 2013).

By presenting observations on how learning climate and LGO may affect the competencies of CSR leaders and which learning activities promote their development, we aim to provide companies and CSR leaders with valuable insights into how CSRC can be stimulated and developed (among selected employees).

\section{Theoretical Background}

\section{CSR Leaders' Competencies}

The literature provides several lists of relevant individual competencies for CSR leaders. Initially researchers, like Wiek et al. (2011) and Rieckmann (2012), identified competencies that students in ESD programs should develop when training for CSR-related professions (e.g., systems and critical thinking, anticipatory competence, and interpersonal competence). Because the competencies needed to accomplish complex tasks-like CSR implementation-are, however, difficult to teach in scholastic settings and are mainly developed on the job (Gulikers 2006), researchers have started to focus on the competencies needed within a business context. In one of the first empirical studies, Willard et al. (2010) defined six key skills (which is a limited concept of competencies) that were needed for success as a CSR leader. Where it came to hard skills, strategic planning, systems thinking, and project management skills were deemed the most important for enabling a strategic approach. With respect to soft skills, communication skills, problem-solving skills, and inspirational skills were deemed to be of key importance. Using a more comprehensive approach to the concept of competence, Osagie et al. (2016a) conducted a mixedmethod study in which they systematically reviewed CSR literature on individual competencies and interviewed CSR 
leaders responsible for the CSR adaptation process. Their analyses resulted in twelve individual CSR-related competencies necessary for the CSR profession: (1) anticipating CSR-related challenges; (2) understanding CSRrelevant systems and subsystems; (3) understanding CSRrelevant standards; (4) CSR management competencies, including (4a) leading CSR programs, (4b) managing CSR programs, and (4c) identifying and realizing CSR-related business opportunities; (5) realizing CSR-supportive interpersonal processes; (6) employing CSR-supportive personal characteristics and attitudes; (7) personal valuedriven competencies, including (7a) ethical normative competencies, (7b) balancing personal ethical values and business objectives, and (7c) realizing self-regulated CSRrelated behaviors and active involvement; and (8) reflecting on personal CSR views and experiences. These twelve CSR competencies have been included in the current study (see Appendix 1 for a more detailed description of these competencies).

\section{Learning Activities for CSR Competence Development}

CSR leaders may employ different learning activities to develop their competencies. Bolhuis and Simons (2001) distinguish four types of learning activities through which competence at work could be improved. First, learning through experience refers to learning by performing tasks assigned to you and by being exposed to and being part of the work context (Nikolova et al. 2014a). New knowledge can be obtained, effective work behaviors can be developed, and competencies can be enhanced through processes of experimentation, socialization, and by observing experienced peers (Lawson et al. 2009). Because CSR leaders often do not have (expert) peers within their organizations whom they can observe and learn the ropes from, most of these processes will likely be less relevant to them. The second learning activity, learning through critical reflection, seems more suitable since it focuses on gaining insights by reflecting on literature, theory, and the ideas of others and by reflecting on one's own behavior, context, values, and past experiences. By thinking these things through, one can learn new ways of acting and working and thereby improve one's competencies (Tynjälä 2008). Since specific literature on the CSR profession is sparse (Osagie et al. 2016a), CSR leaders might learn from ideas and theories from professions with a similar position within their organizations-like safety, health, and quality managers.

Thirdly, learning through theory involves prearranged learning situations (i.e., formal learning) and learning activities such as courses, training, and formal education (cf. vertical learning network; Poell et al. 2000). These learning activities are generally focused on the needs of the majority of the workforce and are often oriented toward enhancing simple competencies. Fourth and finally, learning through social interaction occurs without it being prearranged (informal learning), although it is important that one is aware of the learning in order for the right competencies to be learned. It centers on active interaction with others and involves learning with and from others (Bolhuis and Simons 2001) and includes learning activities such as collaborating with colleagues with a different background and requesting or obtaining feedback from others (Cheetham and Chivers 2001). Van der Krogt (1995) describes how employees are central actors in the learning networks they are part of and co-create. The type of learning networks that professionals co-create and use in order to develop their competencies depends to a large extent on the way in which their work and position are organized and on the dynamics between the various actors within each network (Poell et al. 2000; Van der Krogt 1995, 1998).

Because of their specific position and complex tasks, CSR leaders are unlikely to be the subject of prearranged formal learning interventions. Therefore, we expect that CSR leaders will more often engage in informal learning as opposed to formal learning when developing their competencies, as informal learning activities are more accessible to them. However, as we aim to explore the different ways in which CSR leaders develop their competencies, we have included both formal and informal learning activities in this study.

\section{Competence Development: Contextual and Personal Influences}

Among others, Billett $(2001,2004)$ describes how workrelated learning is affected by the learning opportunities afforded by one's work context. However, he also stresses the importance of "personal agency" (cf. agency theory of Gibson 1966 in Withagen et al. 2012), referring to the fundamental personal values, disposition, and motivation through which learning and experiences are directed and evaluated (Billett 2010a, b). Billett (2001, 2004) argues that employees do not blindly or unquestionably engage in the learning opportunities their work context afford. Although said opportunities may stimulate their learning behavior (cf., Withagen et al. 2012), employees are active agents as to whether, what, and how they learn from these opportunities (Billett 2004; Engeström and Middleton 1996; Klarus 2011). Moreover, the extent to which employees are proactive and engage in learning activities can affect the quality of the learning opportunities they experience in their work context (Billett 2001, 2004), but a reverse relationship is also possible. Therefore, contextual 
as well as personal factors affect one's learning experiences and, as a consequence, one's competence development (Billett 2001; Fuller et al. 2005; Tynjälä 2008). Billett's proposition of an interaction between contextual and individual influences on work-related learning has garnered scientific support (e.g., Bryson et al. 2006; Hodkinson and Hodkinson 2004; Kyndt and Baert 2013) and is now a widely accepted and applied framework (e.g., Billett, 2010a, b; Tynjälä 2008; Illeris 2011).

As different work contexts can elicit different elements of a person's agency behavior (Withagen et al. 2012), it is important to explore which elements of workplace affordances and personal agency affect the competence (development) of CSR leaders.

\section{Learning Climate}

Given the aim of the present study, the company's learning climate is considered a promising theoretical starting point for measuring affordances. This is because it shapes the way employees perceive learning opportunities within their company (Vera-Cruz 2006), thereby affecting the learning behavior of employees (Nikolova et al. 2014b). Nikolova et al. (2014b) conducted an extensive literature review and proposed a three-dimensional conceptualization of learning climate. The first dimension, facilitating learning climate, describes the level to which the company and workplace support, provide, and facilitate learning opportunities for their employees (Kyndt et al. 2009). The second dimension, appreciation learning climate, refers to the degree in which the company rewards learning behavior. The third dimension, error-avoidance learning climate, addresses the extent to which a company focuses on avoiding mistakes. At the individual level (the so-called psychological learning climate or PLC), which is the focus of the current study, these dimensions represent an employee's perception of organizational policies and practices aimed at facilitating, rewarding, and supporting employee learning behavior (cf. James et al. 2008; Nikolova et al. 2014b).

Companies with a psychological facilitating learning climate (or PLC-F; Billett 2004; Fuller and Unwin 2004) are committed to education and provide their employees with sufficient opportunity for improving their competencies. It is through these opportunities that employees learn new ways of doing things (Tynjälä 2008) and develop new competencies or improve existing ones (Bezuijen et al. 2009). A psychological appreciation learning climate (PLC-A; Tracey and Tews 2005) has invitational qualities. Employees are stimulated to engage in the learning opportunities afforded them through financial and non-financial incentives. In addition, employees feel safe because the company is tolerant of learning-related errors, thereby allowing employees to experiment and make mistakes in order to improve their competencies (Marsick and Watkins 2003). In the case of CSR, it is important to facilitate and appreciate learning climates because innovation is an important means through which companies can embed CSR in their DNA (Osagie et al. 2016a; Wijdoogen 2016). Therefore, providing them space and awarding their efforts (i.e., PLC-F and PLC-A) not only enable CSR leaders to do their jobs, it also provides them with the opportunity to develop their competencies. This is why we expect that the competence of CSR leaders will be affected by their PLC-F and PLC-A, and therefore, we formulated the following hypothesis:

H1 PLC-F and PLC-A are positively related to a CSR leader's competencies.

An error-avoidance learning climate (psychological error-avoiding learning climate or $P L C-E$ ) - in contrast to facilitating and appreciating learning climates-hinders competence development (Payne et al. 2007). This type of learning climate is characterized by companies striving to avoid mistakes. This may cause employees to withdraw and feel insecure and/or anxious when they realize that errors may have negative consequences (Carr et al. 2003). If employees are anxious, they are less likely to try new things and make use of learning opportunities (Chillarege et al. 2003; Edmondson2004; Gronewold et al. 2013). Whereas an error-avoidance learning climate is likely to hinder competence development in many professions (Payne et al. 2007), it can be disastrous in the CSR profession; being allowed to experiment is essential for CSR leaders to effectively perform their jobs (Cramer 2003). As it is a new profession and no (perfect) blueprint exists for it, CSR leaders will have to do a lot of pioneering and will likely have to gradually develop their function themselves (Wijdoogen 2016). As learning by doing new things is also a common form of at-work learning (Carmeli et al. 2012), we expect that CSR leaders' competence will be negatively affected by their PLC-E; therefore, we formulated the following hypothesis:

H2 PLC-E is negatively related to CSR leaders' competencies.

\section{Learning Goal Orientation}

An essential motivational aspect related to learning is learning goal orientation (LGO), referring to the motivation to improve one's competencies through learning and training new skills, as well as through learning to complete new and more complex tasks (Dweck and Leggett 1988; VandeWalle 1997). People with a strong LGO tend to view feedback-positive as well as negative-as diagnostically 
relevant information that helps them increase their competencies (VandeWalle 2001).

Previous studies indicated that employees with a stronger LGO are more likely to show proactive behavior and learning behavior (Chughtai and Buckley 2011; Parker and Collins 2010), seek feedback more often (Runhaar et al. 2010; Parker and Collins 2010), and demonstrate higher levels of self-efficacy than employees with a weaker LGO (Payne et al. 2007). Moreover, because individuals with stronger LGO are more confident in their own abilitiesand less anxious about new situations-when compared to employees with a weaker LGO, they are more likely to seek out ways to improve their competencies, engage in uncertain and/or challenging tasks, and set higher goals in said situations (Payne et al. 2007; Sujan et al. 1994). Therefore, differences in LGO might explain differences in CSRC among CSR leaders. Hence, we formulated the following hypothesis:

H3 CSR leaders' LGO is positively related to their CSRC.

\section{An Interaction Between PLC and LGO}

Increasingly, studies on work-related learning focus on the interaction between contextual and personal factors affecting competence development (e.g., Bryson et al. 2006; Dragoni et al. 2009). For instance, employees can be encouraged to behave in alignment with a specific goal orientation through environmental cues. Such cues may restrict the expression of other behaviors by providing information about the most appropriate course(s) of action (Meyer and Dalal 2009). The notion of a potential interaction between contextual influences and one's personal agency is supported by some empirical studies (e.g., Bryson et al. 2006; Dragoni et al. 2009). For example, Bryson et al. (2006) showed that, despite having restrictive learning conditions, vineyard workers who showed high levels of proactive behavior and sought out opportunities to learn often received more opportunities to improve and develop their competencies than workers who did not show such proactive behavior. Similarly, in a study among 351 junior managers, Dragoni et al. (2009) demonstrated that the positive relationship between learning opportunities and managerial competencies was stronger for managers with a stronger LGO than for managers with a weaker one. Therefore, to examine possible interactions between PLC and LGO, in this study we formulated the following hypotheses:

H4 LGO strengthens the effect of PLC-F and PLC-A on CSRC.

H5 LGO acts as a buffer and weakens the negative effect of PLC-E on CSRC.

\section{Methods}

\section{Research Context}

The Dutch approach to CSR is broad, as it includes various themes. Although CSR is a voluntary practice for companies, the Dutch Ministry of Economic Affairs has implemented several policies and interventions intended to promote CSR within Dutch companies. One example of such an intervention is the launch of CSR Netherlands (in Dutch: MVO Nederland) ${ }^{1}$ in 2004. CSR Netherlands is an independent foundation entrusted with the primary task of raising CSR awareness among — and stimulating ownership of it by-Dutch companies in order to increase their involvement in tackling SD challenges. CSR Netherland's efforts seem to have been effective, as a growing number of companies now employ a CSR leader for leading the CSR implementation process (Wijdoogen 2016). We have only included CSR leaders from private companies that were not founded on CSR principles, in order to ensure that their experiences reflect the difficulties faced by CSR leaders in mainstream private businesses (e.g., potential friction between economic interests and CSR objectives, working from a relatively autonomous position).

\section{Sample and Procedure}

Data collection took place in September and October of 2015. All medium-sized and large companies $(n=679)$ that are partners of CSR Netherlands were contacted by phone. The CSR leaders of 130 companies could not be reached, while 322 companies were just setting out on their journey and therefore not actively engaging in CSR yet. In the end, 227 CSR leaders were invited via email to complete an anonymous online questionnaire of which, after a reminder, a total of 195 were completed. After excluding respondents working in public organizations, the final sample numbered 176 CSR leaders (99 males and 98 females); whose mean age was 42.71 ( standard deviation $=9.6$ years); and who either worked in the service industry $(n=117)$ or in manufacturing $(n=59)$. Finally, each CSR leader had either an official managerial $(n=96)$ or non-managerial CSR role $(n=80)$.

\section{Measures}

\section{Learning Activities}

We formulated a list of learning activities based on literature (e.g., Bolhuis and Simons 2001; Cheetham and

\footnotetext{
${ }^{1}$ CSR Netherlands has over 2000 members (partners), including companies, non-governmental organizations (NGOs), education and government agencies, and industry organizations. We approached CSR leaders of partner companies in November 2014.
} 
Chivers 2001). Respondents were instructed to indicate the extent to which each activity contributed to the development of their CSRC. A five-point Likert scale ranging from 1 (not at all) to 5 (very much) was used. In addition, respondents were given the opportunity to suggest learning activities that were not included in this list.

\section{CSR Competence}

The twelve CSR competencies identified by Osagie et al. (2016a, b; see Appendix 1) were used to assess the CSR competence of CSR leaders. Based on these twelve CSRCs, four to six items were formulated for each CSRC. These items were then discussed with four CSR leaders. The items receiving the most support among them were included. Furthermore, although it is possible to theoretically distinguish specific competencies and/or elements of competencies, in practice being competent is often the result of a set of highly interrelated competencies (Delamare Le Deist and Winterton 2005); this resulted in the items being highly correlated. For this reason, and because we wanted to keep the questionnaire as concise as possible, we decided to measure the twelve competencies as one construct by including the items with the highest loading on each CSRC. For the first 11 items, the respondents were instructed to score themselves on a commonly used grading scale in the Netherlands, a scale ranging from 1 to 10 , including an additional score of "11" (meaning "not applicable"); see Table 1 for these 11 items. For the 12 th item (the personal characteristic element of CSRC-Osagie et al. 2016a), the following statement was formulated: "I see myself as being inventive in the preparation/implementation of our sustainability program." For this item, we used a five-point Likert scale ranging from 1 (totally disagree) to 5 (totally agree). A single score for CSR competence was then calculated for each respondent by taking the average of the standardized scores for these items. A higher mean score indicates higher perceived competence in tasks related to CSR implementation.

\section{Psychological Learning Climate}

PLC-F, PLC-A, and PLC-E were measured using the validated workplace learning climate questionnaire published by Nikolova et al. (2014a). All items (three per dimension) were measured on a five-point Likert scale ranging from 1 (totally disagree) to 5 (totally agree). Example items include "My organization provides sufficient resources to develop my competencies (PLC-F; Cronbach's $\alpha=0.80$ )"; "In my organization, employees who make an effort to learn new things earn both appreciation and respect (PLC-A; Cronbach's $\alpha=0.73$ )"; and "In my organization, employees do not dare to discuss mistakes (PLC-E, Cronbach's $\alpha=0.85)$." A higher mean score on these three scales indicates that the respondent perceived the learning climate in the companies as being more

Table 1 Factor loadings for exploratory factor analysis with varimax rotation of CSRC scale

\begin{tabular}{ll}
\hline Construct & Items \\
\hline $\begin{array}{c}\text { CSR } \\
\text { competence }\end{array}$ & $\begin{array}{c}\text { Factor } \\
\text { loadings }\end{array}$ \\
example regarding the environment, politics, technology, and/or society) \\
02: I am able to identify those practices my company undertakes that have the highest impact (positive as well as \\
negative) on the sustainability challenges relevant to us \\
03: I am able to assess the sustainability performance of my organization in light of what our sector judges to be \\
"good sustainability practices" \\
04: I am able to develop my company's strategic sustainability objectives into a sustainability program \\
05: I am able to utilize my own network to influence decision-making concerning sustainability in my company \\
06: I am able to pay extra attention-where necessary-to the content or the change process to achieve the desired \\
sustainability objectives (e.g., in the case of resistance to change) \\
07: I am able to encourage others to raise the bar where it comes to sustainability in their work \\
08: I am able to translate my own ideals concerning sustainability into a practical approach to sustainability \\
challenges \\
09: I am able to cope with possible conflicts between the seriousness and urgency of sustainability challenges and the \\
possibilities in my company for addressing these issues \\
10: I am able to actively make myself available to perform/coordinate sustainability interventions \\
11: I am able to adjust my thinking based on the lessons I have learned from previous experiences as a sustainability \\
professional \\
12: I see myself as being inventive in the preparation/implementation of our sustainability program
\end{tabular}

CSR Corporate Social Responsibility, CSRC CSR competence 
facilitating and appreciating and oriented toward error avoidance, respectively.

\section{Learning Goal Orientation}

LGO was measured using the five-item scale developed by VandeWalle (1997), with a five-point Likert scale ranging from 1 (totally disagree) to 5 (totally agree). This scale was chosen because it was specifically developed and validated for a broad range of professions. An example item is "I often look for opportunities to develop new skills and knowledge" (Cronbach's $\alpha=0.77$ ). A higher mean score indicates a stronger LGO.

\section{Control Variables}

Age, education, tenure, CSR role (non-managerial vs. managerial), company size, and organizational financial situation were included as control variables in the correlation analysis, as these factors have been linked to competence development in previous studies (e.g., Kyndt and Baert 2013). Only those variables that significantly correlated with one or more of the variables under study were included in the regression analysis.

\section{Data Analyses}

To determine which learning activities can help stimulate CSRC, we used the average scores of each learning activity in order to rank them on the basis of their means within each of the four ways to improve one's competencies as described by Bolhuis and Simons (2001). The learning activities proposed by respondents were evaluated. These activities were actually specifications of activities listed in the survey and are therefore presented as examples (e.g., meetings with peers, working in multi-stakeholder collaborations).

A principal component analysis was performed (Table 1) in order to identify the significant components underlying the respondents' choices for the 12 statements measuring CSRC. To determine the number of factors to extract, we performed a parallel analysis (O'Connor 2000). A single component was extracted with all loadings $>.40$ and was labeled "CSR competence" $(\alpha=.91)$.

Using SPSS AMOS 22 (IBM Co.), a confirmatory factor analysis (CFA) was conducted for the LGO and PLC scales, using established goodness-of-fit indices $(\mathrm{Hu}$ and Bentler 1999). A four-factor model produced an acceptable fit $\left(\chi^{2}\right.$ $(71)=94.23, p<.05 ; \quad$ RMSEA $=.043 ; \quad$ SRMR $=.045$; $\mathrm{NNFI}=.97 ; \mathrm{CFI}=.97$; IFI $=.98)$ with all items loading $\geq .40$ on their respective scales. There were no indications of problematic cross-loading of items on other factors. Moreover, this model had a significantly better fit than a two-factor model [with all PLC items loaded on one factor and all LGO items loaded on another factor $\left.\left(\Delta \chi^{2}(5)=191.13, p<.001\right)\right]$ and a one-factor model [with all items loaded on a single factor $\left.\left(\Delta \chi^{2}(6)=434.76, p<.001\right)\right]$.

To test our hypotheses, we performed a hierarchical regression analysis in which we first centered the independent variables to reduce issues related to multicollinearity (Aiken and West 1996). In Model 1, we entered the control variables into the model. In Model 2, we entered PLC-F, PLC-A, and PLC-E into the model. In Model 3, we entered LGO. And finally, in Model 4, we entered all possible twoway interactions into the model. We limited our analyses to two-way interactions for interpretation reasons and to maintain sufficient statistical power in order to obtain robust, meaningful results. Effect sizes were calculated for Models 2, 3, and 4 using Cohen's $f^{2}$. An effect size was considered small, medium, or large if Cohen's $f^{2}$ was 0.02 , 0.15 , or 0.35 , respectively (Cohen 1988).

\section{Results of Learning Activities for Developing CSRCs}

Table 2 shows the ranking of the learning activities for the development of CSRC. "Learning through interaction" $\left(M_{\text {category }}=3.85\right)$ was the activity most often deployed in developing CSRC, followed by "learning through critical reflection" $\left(M_{\text {category }}=3.78\right)$, "learning through experience" $\left(M_{\text {category }}=3.60\right)$, and "learning through theory" $\left(M_{\text {category }}=2.35\right)$. Looking at the averages of all learning activities, "discussions with others" $(M=4.19)$, "collaborating with others" $(M=4.19)$, and "asking advise from others" ( $M=4.00)$ were the activities that were most often suggested for developing one's CSRC. The CSR leaders emphasized that "others" could refer both to people or groups inside and outside of their own company. Specific activities suggested by the CSR leaders included meeting with other CSR leaders; participating in think tanks; visiting and asking advice from pioneering companies and CSR leaders; collaborating in multi-stakeholder partnerships; and collaborating with startups. The formal learning activities-"participating in online or offline training/courses" $(M=2.47)$ and "participating in formal education" ( $M=2.22)$-were the activities least commonly employed when developing CSRC.

\section{Results of the Influence of PLC and LGO on CSRC}

\section{Descriptive Statistics of Variables Included in Hypothesis Testing}

The descriptive statistics and correlations among CSRC, LGO, PLC-F, PLC-A, and PLC-E are summarized in 
Table 2 Ranking of the learning activities used by CSR leaders to develop CSRC

\begin{tabular}{|c|c|}
\hline Learning activities & $M(\mathrm{SD})$ \\
\hline \multicolumn{2}{|l|}{ A. Learning through social interaction $\left(M_{\text {category }}=3.85\right)$} \\
\hline 1. Discussions with others & $4.19(.72)$ \\
\hline 2. Collaborating with others & $4.19(.78)$ \\
\hline 3. Asking questions of/obtaining advice from others (e.g., colleagues with more or less experience, experts) & $4.00(.78)$ \\
\hline 4. Getting feedback from others & $3.94(.78)$ \\
\hline 5. Training others & $2.91(1.2)$ \\
\hline \multicolumn{2}{|l|}{ B. Learning through critical reflection $\left(M_{\text {category }}=3.78\right)$} \\
\hline 1. Reflecting on experiences & $3.91(.80)$ \\
\hline 2. Evaluating/checking the information obtained & $3.64(.75)$ \\
\hline \multicolumn{2}{|l|}{ C. Learning through experience $\left(M_{\text {category }}=3.60\right)$} \\
\hline 1. Looking for information (e.g., in books or on the Internet) & $3.86(.84)$ \\
\hline 2. Observing and imitating others (e.g., role models) & $3.56(.92)$ \\
\hline 3. Experimenting & $3.53(.96)$ \\
\hline 4. Performing in-role and extra-role tasks & $3.45(.94)$ \\
\hline \multicolumn{2}{|l|}{ D. Learning through theory $\left(M_{\text {category }}=2.35\right)$} \\
\hline 1. Participating in online and offline training/course (courses shorter than 1 year) & $2.47(1.2)$ \\
\hline 2. Participating in formal education (courses 1 year or longer) & $2.22(1.3)$ \\
\hline
\end{tabular}

CSR Corporate Social Responsibility, CSRC CSR competence

Table 3 Descriptive statistics and correlations among study variables

\begin{tabular}{|c|c|c|c|c|c|c|c|c|c|c|c|c|c|}
\hline & Mean & SD & 1 & 2 & 3 & 4 & 5 & 6 & 7 & 8 & 9 & 10 & 11 \\
\hline 1. CSRC & 0.00 & .70 & 1 & & & & & & & & & & \\
\hline 2. PLC-F & 3.63 & .71 & $.22 * *$ & 1 & & & & & & & & & \\
\hline 3. PLC-A & 3.41 & .66 & $.20 * *$ & $.55^{* *}$ & 1 & & & & & & & & \\
\hline 4. PLC-E & 2.56 & .87 & $-.21 * *$ & $-.35 * *$ & $-.47 * *$ & 1 & & & & & & & \\
\hline 5. LGO & 4.13 & .50 & $.41 * *$ & .11 & .13 & -.10 & 1 & & & & & & \\
\hline 6. Financial situation & 2.93 & .98 & -.01 & .09 & .07 & $-.17 *$ & .08 & 1 & & & & & \\
\hline 7. Company size & 3.46 & .82 & $.16^{*}$ & .08 & .10 & -.06 & .02 & -.07 & 1 & & & & \\
\hline 8. Age & 42.71 & 9.5 & $.22 * *$ & $.23 * *$ & .14 & -.09 & .06 & .08 & -.04 & 1 & & & \\
\hline 9. Role & .55 & .50 & .14 & .08 & $.16^{*}$ & -.14 & $.24 * *$ & .15 & -.14 & $.18^{*}$ & 1 & & \\
\hline 10. Education & 5.59 & .86 & .08 & .03 & .08 & .04 & .15 & -.01 & $.30^{* *}$ & -.13 & -.05 & 1 & \\
\hline 11. Job tenure & 6.57 & 5.2 & .07 & .10 & .07 & -.06 & -.11 & -.09 & -.09 & $.40 * *$ & -.09 & -.08 & 1 \\
\hline
\end{tabular}

CSRC CSR competence, based on standardized scores, $P L C-F$ psychological facilitating learning climate

$P L C$-A psychological awarding learning climate, $P L C$ - $E$ psychological error-avoiding learning climate

$L G O$ Learning goal orientation. Role dummy coded (non-managerial $=0$, managerial $=1$ ). $* p<.05$, ** $p<.000$

$N=176$

Table 3. Among the control variables, only company size, company financial situation, age, and the CSR leaders' roles significantly correlated with at least one variable under study. The PLC variables correlated weakly to moderately with each other, and all of these variables significantly correlated with CSRC in the expected direction. None of the PLC variables correlated significantly with LGO.

\section{Hypothesis Testing}

Table 4 summarizes the results of the regression analysis. Company size $(\beta=.18, p<.05)$ and age $(\beta=.20$, $p<.05)$ were positively correlated with CSRC, indicating that older CSR leaders and CSR leaders who worked for larger companies reported higher levels of CSRC. 
Table 4 Hierarchical regression analyses with PLC-F, PLC-A, PLC-E, and LGO as predictors of CSR competence

\begin{tabular}{|c|c|c|c|c|c|c|c|c|c|c|c|c|}
\hline & \multicolumn{3}{|c|}{ Model 1} & \multicolumn{3}{|c|}{ Model 2} & \multicolumn{3}{|c|}{ Model 3} & \multicolumn{3}{|c|}{ Model 4} \\
\hline & $B$ & $\mathrm{SE}$ & $\beta$ & $B$ & SE & $\beta$ & $B$ & SE & $\beta$ & $B$ & SE & $\beta$ \\
\hline \multicolumn{13}{|l|}{ Control variables } \\
\hline Financial situation & -0.02 & .05 & -.03 & -0.04 & .05 & -.06 & -0.05 & .05 & -.08 & -0.06 & .05 & -.08 \\
\hline Company size & 0.15 & .06 & $.18 *$ & 0.13 & .06 & $.16^{*}$ & 0.12 & .06 & $.14^{*}$ & 0.14 & .06 & $.16^{*}$ \\
\hline Age & 0.02 & .01 & $.20 *$ & 0.01 & .01 & $.17 *$ & 0.01 & .01 & $.17 *$ & 0.02 & .01 & $.20 *$ \\
\hline Role & 0.19 & .11 & .14 & 0.16 & .11 & .11 & 0.04 & .10 & .03 & 0.02 & .10 & .01 \\
\hline \multicolumn{13}{|l|}{ Predictors } \\
\hline PLC-F & & & & 0.11 & .09 & .11 & 0.09 & .08 & .09 & 0.05 & .09 & .06 \\
\hline PLC-A & & & & 0.03 & .10 & .03 & 0.01 & .09 & .01 & 0.06 & .09 & .05 \\
\hline PLC-E & & & & -0.11 & .07 & -.13 & -0.10 & .07 & -.13 & -0.07 & .06 & -.09 \\
\hline LGO & & & & & & & 0.53 & .10 & $.38^{*}$ & 0.56 & .10 & $.39 *$ \\
\hline \multicolumn{13}{|l|}{ Moderators } \\
\hline PLC-F*PLC-A & & & & & & & & & & 0.23 & .09 & $.22 *$ \\
\hline PLC-F*PLC-E & & & & & & & & & & 0.27 & .10 & $.30 *$ \\
\hline PLC-A*PLC-E & & & & & & & & & & 0.01 & .10 & .01 \\
\hline LGO*PLC-F & & & & & & & & & & -0.15 & .17 & -.08 \\
\hline LGO*PLC-A & & & & & & & & & & -0.03 & .21 & -.02 \\
\hline LGO*PLC-E & & & & & & & & & & -0.08 & .13 & -.05 \\
\hline$R^{2}$ & & .09 & & & .14 & & & .27 & & & .33 & \\
\hline Adjusted $R^{2}$ & & .07 & & & .10 & & & .23 & & & .26 & \\
\hline$\Delta R^{2}$ & & & & & $.04 *$ & & & $.13 * *$ & & & $.06^{*}$ & \\
\hline$f^{2}$ & & & & & .16 & & & .37 & & & .47 & \\
\hline
\end{tabular}

CSRC CSR competence, $P L C$ - $F$ psychological facilitating learning climate. $P L C$ - $A$ psychological awarding learning climate, $P L C-E$ psychological error-avoiding learning climate, $L G O$ learning goal orientation. Role dummy coded (non-managerial $=0$, managerial $=1$ ). $* p<.05$, $* * p<.000 . N=176$

With respect to $\mathrm{H} 1$ and $\mathrm{H} 2$, we predicted that PLC-F and PLC-A would positively correlate with CSR leaders' CSRC and that PLC-E would negatively correlate with CSRC. Although the relationships went in the expected direction, the relationships between CSRC and PLC-F ( $\beta=.11, p>.05)$, PLC-A ( $\beta=.03, p>.05)$, and PLC-E $(\beta=-.13, p>.05)$ were not significant when controlled for the other variables in the model. Therefore, $\mathrm{H} 1$ and $\mathrm{H} 2$ are not supported by our results.

Next, we tested the hypothesis that LGO would relate positively to CSRC. This hypothesis (H3) is supported by the data, as the results show that CSR leaders with a stronger LGO perceive themselves as more competent in driving the transitions in CSR implementation $(\beta=.38$, $p<.05)$; adding LGO to the model yielded a large effect on CSRC $\left(f^{2}=.37 ; R^{2}=.27\right)$. Furthermore, the relationship between LGO and CSRC remained significant after we entered all two-way interaction terms into the model (see Table 4, Model 4), indicating that a strong LGO can enhance CSRC.

With respect to hypotheses 4 and 5, we expected that LGO would regulate the relationships between CSRC and PLC-F, PLC-A, and PLC-E. We, however, found no significant two-way interaction effects between LGO and PLC-F $(\beta=-.08, p>.05)$, PLC-A $(\beta=-.02, p>.05)$, or PLC-E $(\beta=-.05, p>.05)$ on CSRC. Therefore, H4 and H5 were not supported by the data. However, as companies can have several types and dimensions of climates simultaneously (Schneider et al. 2013), we decided to assess potential interaction effects between the PLC dimensions. The analysis showed significant interaction effects between PLC-F and PLC-A $(\beta=.22, p<.05)$ and between PLC-F and PLC-E $(\beta=.30, p<.05)$. Further examination of these interaction effects showed that when PLC-F was low, there was no effect of PLC-A ( $B=-.10$, $p>.05)$ and there was a significant negative effect of PLC$\mathrm{E}(B=-.26, p<.05)$ on CSRC (see Figs. 1 and 2). In contrast, when PLC-F was high, there was a positive effect of PLC-A $(B=.22, p<.05)$ and no effect of PLC-E $(B=.13, n s)$ on CSRC. These results indicate that an awarding learning climate can enhance the competence of CSR leaders only when they are also facilitated with ample opportunity to learn. Moreover, these results indicate that an error-avoidance learning climate can be detrimental to a CSR leader's competence in cases where leaders feel they have but few opportunities to learn. 


\section{Discussion and Conclusions}

The aim of this study was to explore the following two research questions (1) Which learning activities are employed by CSR leaders to develop their competencies? and (2) How are CSR leaders' competencies affected by contextual and personal work-related factors?

\section{Learning Activities for Developing CSR Competencies (CSRCs)}

With respect to the first research question, we addressed a gap in the literature as to how individual CSR-related competencies can be developed by CSR leaders in order to stimulate the CSR implementation process. Our study helps to narrow this gap by showing that external learning networks in particular are seen as a valuable way for CSR leaders for developing their CSRC. Our results indicate that CSR leaders most often engage in learning activities that involve "learning through social interactions" (like discussions and collaborations). The CSR leaders explicitly emphasized the importance of learning from others outside of their companies, for example by engaging in think tanks and by visiting pioneering companies and asking advice from their CSR leaders. Learning in formal educational settings (i.e., learning through theory) was the activity least employed. The complexity of SD challenges, the fact that CSR leaders must work extensively with external stakeholders when tackling SD challenges, and the relatively autonomous and solitary position CSR leaders occupy within their company might explain why they put emphasis on learning from others outside it. Forming learning networks with others inside the company, in order to develop the necessary competencies, might not be the ideal option for CSR leaders, nor is it even necessarily an available

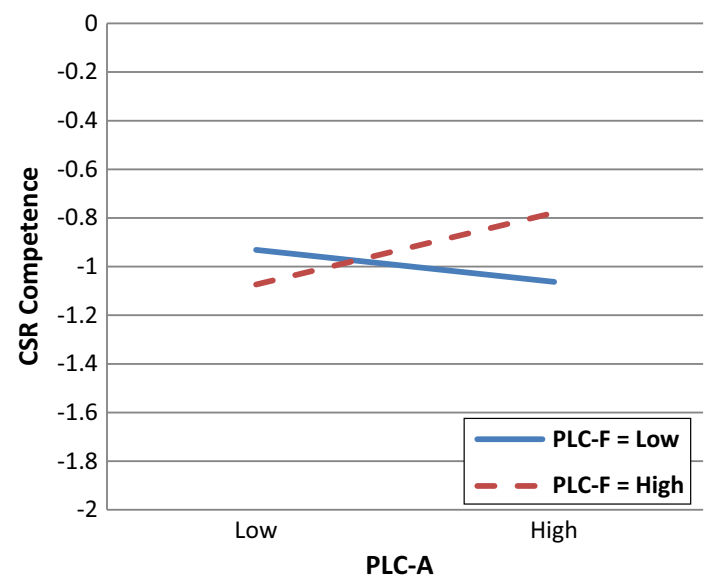

Fig. 1 CSR competence as a function of PLC-F and PLC-A. Note. $P L C-F$ psychological facilitating learning climate, $P L C-A$ psychological awarding learning climate

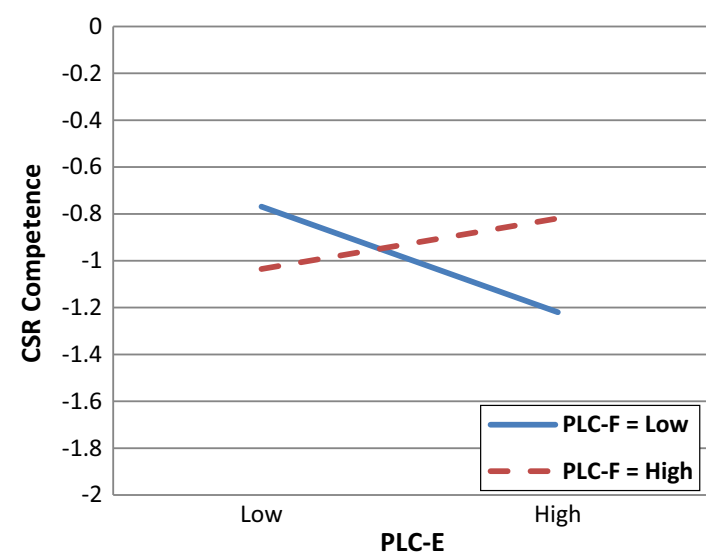

Fig. 2 CSR competence as a function of PLC-F and PLC-E. Note. $P L C-F$ psychological facilitating learning climate, PLC-E psychological error-avoiding learning climate

option. Consequently, CSR leaders seek out peers outside of their companies and establish external learning networks in order to learn from others.

\section{Contextual and Personal Influences on CSRC}

With the second research question of this study, we addressed another gap in the literature regarding the development of CSRC. We explored whether the psychological learning climate (PLC) and learning goal orientation (LGO) could help explain differences in CSRC among various CSR leaders. Based on the results, we concluded that the influence of PLC might not be as straightforward as we expected. Moreover, we concluded that LGO might play a central role in promoting the competence of CSR leaders in leading the CSR implementation process. To arrive at these conclusions, we tested several hypotheses. First, contrary to what we expected, there was no main effect of the way in which CSR leaders view their learning climate as facilitating (PLC-F), as awarding (PLC-A), or as error avoiding (PLC-E). These results seem to contradict previous studies that did find a significant main effect of PLC on work-related learning (see Kyndt and Baert 2013 for a review) and competencies (Dragoni et al. 2009). However, researchers often focus on one specific PLC dimension in these studies, thereby ignoring potential effects of other PLC dimensions (cf. Armstrong-Stassen and Schlosser 2008; Dragoni et al. 2009). For example, Dragoni et al. (2009) found a positive relationship between PLC and managerial competencies, but they only focused on the extent to which companies provide their managers with ample opportunities to learn (i.e., PLC-F). However, research shows that companies can have different climates simultaneously. Moreover, though each climate can show unique influences-as they reinforce or restrict specific parts of one's behavior - they can each also influence the effect of the others through common denominators (e.g., 
Schneider et al. 2013). Research furthermore shows that clear and consistent environmental cues can reinforce the intended outcome, while inconsistent cues force the employee to decode ambiguous messages themselves, which can lead to unwanted outcomes (cf. Bowen and Ostroff 2004). Thus, in terms of the study variables, PLC-F and PLC-A could potentially reinforce each other's effects as they are both beneficial to competence development, while PLC-Ewhich is detrimental to learning - can potentially weaken or perhaps block the effect of PLC-F and PLC-A on CSR leaders' competence in leading CSR implementation.

We assessed the possibility of an interaction effect between the PLC dimensions through post hoc analyses and found some support for this supposition. The findings show that rewarding CSR leaders for learning (PLC-A) may promote their CSRC, but only if they are also given ample opportunity to learn (PLC-F). What is more, a PLCE will negatively affect the competence of CSR leaders only when few opportunities to learn are available to them. Clearly, more research is needed to determine the exact interplay between the PLC dimensions and CSRC. Nevertheless, our findings add to previous research by showing that the influence of PLC on the learning outcomes of employees (i.e., CSRC) might change when we account for the fact that people can have distinct simultaneous experiences with respect to the PLC dimensions.

Next, as expected, we found that a CSR leader's LGO can help enhance their competence. However, contrary to what we predicted, this relationship is not affected by how CSR leaders experience their company's learning climate. Our expectation was based on Billett's (2001, 2010a, b) framework, in which competence development at work is an outcome of the interaction between someone's personal agency and contextual factors. It is unclear why we did not find such an interaction effect between the PLC dimensions and LGO. It might be that the interrelation between the PLC dimensions and LGO varies with the different roles (i.e., managerial vs. non-managerial) CSR leaders play in the implementation process. The significant correlation between "Role" and LGO $(r=.24)$ provides some indication for this suggestion.

Furthermore, the fact that CSR leaders explicitly stressed "learning from others outside the company" might also provide a clue for the lack of interaction effects of PLC and LGO on CSRC. It indicates that the learning opportunities provided from within the companies (e.g., "vertical learning network"; Poell et al. 2000)—although supportive to CSR leaders' learning processes-are simply not sufficient for the development of the necessary competencies, thereby driving these leaders to seek external sources for competence development. The focus on the external world is inherent in their job as it requires them, more than in any other corporate position, to work extensively with external stakeholders due to the wicked nature of SD challenges. Therefore, CSR leaders might be less influenced by-or less aware of-the opportunities offered by the internal learning climate than other employees. Furthermore, they might have created what Poell et al. (2000) have termed a "liberal learning network" in order to develop their competencies. In such a learning network, there is little interference from the company in an individual's learning. Professionals direct their own learning and create their own relevant learning situations. This suggestion of a liberal learning network is reinforced by the high mean LGO score ( $M=4.13$ on a scale from 1 to 5$)$, which shows that the CSR leaders included in our study perceive themselves as strongly learning goal oriented. Such individuals are likely to take charge of their own learning processes (i.e., selfdirected learning), as they are confident in their abilities and proactively seek for opportunities to improve their own competencies (Payne et al. 2007; Sujan et al. 1994). Therefore, the effect of LGO might overrule the effects of the PLC dimensions.

Still, more research is needed to provide conclusive answers as to why there is no interaction effect of PLC and LGO on CSRC. Our results nevertheless suggest that, in a CSR context, the interaction proposition of Billett (2001) might not be as straightforward as the framework suggests. It is possible that the relationship between LGO and PLC is more complex than could be assessed in this study.

\section{Study Limitations and Suggestions for Further Research}

Our results provide insight into how CSR leaders' competencies can be developed. Nevertheless, several issues with respect to the study design should be considered when interpreting these results. First, to explore how-and through which learning activities-CSR leaders can develop their competencies, we provided them with a structured list of learning activities and instructed them to indicate the extent to which each activity contributed to the development of their CSRC. In order to reach more depth, future studies might interview CSR leaders as a means to explore why certain learning activities should be emphasized, if and why they find PLC less important for enhancing their competence, and whether their jobs and/or positions elicit the above-mentioned liberal learning network. Second, dealing with (global) SD challenges requires collaboration among different stakeholders. Future research should therefore take competencies needed for working in multi-stakeholder alliances into account as well. Third, it was difficult to locate CSR leaders for this study. This is owing to the fact that the CSR profession is a relatively new one, and although they have similar missions and job descriptions, in practice CSR leaders are 
denominated by a vast array of different job titles. As such, we used a convenience and a referral sampling method to locate and invite CSR leaders to participate in this study. Although we contacted each respondent via email to ensure they were working in companies that were active in CSR and registered with "CSR Netherlands," this sampling method nevertheless limits the generalizability of our study results which should be kept in mind before making overgeneralizations based on them.

Fourth, the study design was cross-sectional, which limited our measurement of the competence of CSR leaders to a one-time view of their current self-perceived competence. Moreover, this design precluded our ability to draw definitive causal inferences based on the results. Finally, we used a self-reporting tool to measure all variables. Such an approach can inappropriately elicit socially desirable responses regarding one's LGO (and one's CSRC in particular) and elicit common method variance (CMV) among the variables included in the analysis; as such, it could have inflated the correlations found between some variables. Podsakoff et al. (2003) have discussed several statistical techniques through which one could get an indication of the amount of common method variance in one's research. Many of these techniques, however, require one to perform a confirmative factor analysis, which we found inappropriate here because our CSRC measure requires further validation using a different sample (cf. besides the fact that the influence of a common method variance might be overestimated-Spector 2006). We implemented several of the procedural remedies proposed by Podsakoff et al. (2003), like guaranteeing response anonymity. Nevertheless, we recommend that future studies assess CSRC and LGO by several methods and employing several sources in its measurement, like a supervisor's judgment of proposed competence or a past competence assessment in addition to the professional's rating of their own competence.

\section{Practical Implications}

The CSR profession is still in its infancy, and information about how to develop the appropriate competencies to effectively manage the transition toward CSR is essential to its maturation. The findings that current CSR leaders most often use learning activities that center on learning with, and from, others outside their own company and that current learning activities provided within companies are likely to be inadequate for CSR leaders, can be instrumental for human resource professionals and CSR leaders in helping them decide on appropriate activities for CSR competence development. By facilitating self-directed learning by CSR leaders, companies can help nourish external learning networks, for instance peer meetings; participation in think tanks; and inviting and/or visiting pioneering companies and other CSR leaders. In addition, our results highlight the importance of one's LGO in promoting CSRC. It is therefore important to recruit employees with a strong LGO in order to drive the changes needed for CSR implementation. Having such an LGO will increase the likelihood that these CSR leaders will engage in continuous learning, thereby ensuring that they maintain the necessary competencies for cementing their role in implementing CSR.

Open Access This article is distributed under the terms of the Creative Commons Attribution 4.0 International License (http://crea tivecommons.org/licenses/by/4.0/), which permits unrestricted use, distribution, and reproduction in any medium, provided you give appropriate credit to the original author(s) and the source, provide a link to the Creative Commons license, and indicate if changes were made.

\section{Appendix 1}

See Table 5 .

Table 5 Individual CSR-related competencies

\begin{tabular}{|c|c|}
\hline Competence label & Competence description \\
\hline \multicolumn{2}{|l|}{ Cognition-oriented competence domain } \\
\hline 1. Anticipating CSR-related challenges & $\begin{array}{l}\text { The CSR leader must be able to mentally construct scenarios to describe how CSR-related } \\
\text { challenges will develop in the future and how these challenges might affect the company. } \\
\text { This definition includes the ability to think critically and anticipate potential consequences } \\
\text { for future local and global CSR-related challenges of decisions made by the company } \\
\text { today }\end{array}$ \\
\hline $\begin{array}{l}\text { 2. Understanding CSR-relevant systems and } \\
\text { subsystems }\end{array}$ & $\begin{array}{l}\text { Systems thinking is the ability to identify and understand relevant socio-ecological systems } \\
\text { from different domains and disciplines and reflect on their interdependency. This } \\
\text { competence has both an internal component and an external component. Here, "external } \\
\text { component" refers to the ability to have a system-wide perspective on CSR challenges. } \\
\text { The "internal component" reflects the notion that the company is perceived as a system } \\
\text { comprised of several interdependent subsystems (i.e., business units and disciplines). In } \\
\text { this internal perspective, "systems thinking" refers to the ability of a CSR leader to } \\
\text { analyze CSR-related challenges in an interdisciplinary manner }\end{array}$ \\
\hline
\end{tabular}


Table 5 continued

Competence label Competence description

3. Understanding CSR drivers, CSR standards, and CSR regulations.

Functional-oriented competence domain

4a. CSR leadership competencies

4b. Identifying and realizing CSR-related business opportunities

4c. Managing CSR implementation

Social-oriented competence domain

5. Realizing CSR-supportive interpersonal processes

Meta-oriented competence domain

6. Employing CSR-supportive personal characteristics and attitudes

7a. Ethical normative competencies

7b. Balancing personal ethical values and business objectives
When faced with CSR challenges, a CSR leader must understand how the company should cope with and apply important industrial regulations (e.g., collective industrial standards and integrity pacts), national and international regulations, political processes, and corporate governance (such as codes of conduct). Moreover, the CSR leader should be able to contribute to the development of these standards, for example by participating in roundtable meetings

The CSR leader must be able to develop a CSR vision and give the company's CSR program direction. This includes being prepared to take risks and seeks new ways to pursue CSR (i.e., being a pioneer) and thinking about future CSR developments, as well as how those developments might affect the company's current CSR program

A CSR leader should also have entrepreneurial competencies. Thus, the CSR leader should be alert to trends in CSR and should be able to translate and realize these developments into business opportunities for the company. In order to do so, the CSR leader must have at least some business, organizational, and sector-specific knowledge, and the CSR leader must be able to make a business case for CSR. At the same time, the professional must not lose sight of the bigger picture (i.e., tackling local and global CSR challenges) and should therefore avoid the trap of thinking in terms of short-term financial gains. Moreover, to realize CSR-related business opportunities, the professional must be able to deal with the company's formal and informal decision-making processes and its organizational politics and culture

These change management-related and program management-related competencies include the ability to lead the transition toward CSR, to develop crucial alliances with important individuals both inside and outside the company, and to deal with "resistance to change" by inspiring and motivating others. The CSR leader must be able to translate a strategy into individual milestones, targets, and concrete actions. The CSR leader must also be able to organize, facilitate, and manage this process and the people involved, all within the specified timeframe and budget. To do so, the professional must have good problemsolving skills, and he/she must be able to prepare reports and present results in a clear and convincing manner

The CSR leader must have good social, communication, and networking skills, as he/she must be able to raise awareness of CSR, as well as challenge and stimulate ownership of CSR in others. Moreover, the CSR leader should be able to coach and help others integrate CSR into their daily work. Finally, the CSR leader must be able to work well in multidisciplinary and multicultural collaborations, and he/she must be able to represent the company's interests while mapping and showing respect to distinctive ideas and inputs of stakeholders

When implementing CSR in his/her company, the CSR leader must deal with various stakeholders, each of whom can have their own unique interests. Moreover, CSR implementation is a process of change that involves changing people's mindset. Therefore, CSR leaders often encounter resistance to change and will need to possess certain personal characteristics and attitudes in order to address these challenges. The most commonly mentioned features include patience, resilience, flexibility, a realistic attitude, pragmatism, innovativeness, empathy, and a positive attitude

The CSR leader is convinced of the urgency of CSR challenges and is intrinsically driven (i.e., intrinsically motivated) to address these challenges. This competence involves the ability to apply one's personal ethical standards and values while assessing CSR-related issues

This competence is functionally oriented and includes the ability to strike a balance between idealism and pragmatism. Thus, the CSR leader must have the adaptive capacity to pursue both financial objectives and CSR objectives without losing sight of (or overstepping) his/ her personal ethical boundaries and values 
Table 5 continued

\begin{tabular}{ll}
\hline Competence label & Competence description \\
\hline $\begin{array}{l}\text { 7c. Realizing self-regulated CSR-related } \\
\text { behaviors and active involvement }\end{array}$ & $\begin{array}{r}\text { This competence involves the ability to apply one's personal ethical standards and values to } \\
\text { CSR implementation. The CSR leader feels personally responsible for behaving ethically } \\
\text { and assumes this responsibility. The CSR leader is actively involved in the implementation } \\
\text { of CSR by being action oriented and decisive; the CSR leader also serves as a role model } \\
\text { for others by performing CSR-related activities. This competence is functionally oriented } \\
\text { and is interpreted in practice as the congruence between what you stand for, what you say, } \\
\text { and what you do }\end{array}$ \\
$\begin{array}{l}\text { This competence includes the ability to recognize and challenge one's own prior ideas, } \\
\text { habits, and assumptions, as well as the ability to derive meaning from this self-evaluation. } \\
\text { experiences }\end{array}$ & $\begin{array}{l}\text { Thus, CSR leaders use self-evaluation and self-learning approaches when working on CSR } \\
\text { challenges }\end{array}$ \\
\hline
\end{tabular}

\section{References}

Aiken, L. S., \& West, S. G. (1996). Multiple regression: Testing and interpreting interactions. Thousand Oaks, CA: Sage.

Armstrong-Stassen, M., \& Schlosser, F. (2008). Benefits of a supportive development climate for older workers. Journal of Managerial Psychology, 23, 419-437.

Bertels, S., Papania, L., \& Papania, D. (2010). Embedding sustainability in organizational culture: A systematic review of the body of knowledge. London, Canada: Network for Business Sustainability.

Bezuijen, X., Van den Berg, P. T., Van Dam, K., \& Thierry, H. (2009). Pygmalion and employee learning: The role of leader behaviors. Journal of Management, 35, 1248-1267.

Billett, S. (2001). Learning through work: Workplace affordances and individual engagement. Journal of Workplace Learning, 13(5), 209-214.

Billett, S. (2004). Workplace participatory practices: Conceptualising workplaces as learning environments. Journal of Workplace Learning, 16, 312-324.

Billett, S. (2010a). Learning in and for working life: a relational interdependence between personal and social agency. In M. Van Woerkom \& R. Poell (Eds.), Understanding learning in the workplace. Concepts, measurement and application. London: Routledge.

Billett, S. (2010b). Workplace Learning Frameworks. In P. Peterson, E. Baker, \& B. McGaw (Eds.), International Encyclopaedia of Education (Vol. 1, pp. 58-63). Oxford, UK: Elsevier.

Bock, G., Zmud, R. W., Young-Gul, K., \& Lee, J.-N. (2005). Behavioral intention formation in knowledge sharing: examine the roles of extrinsic motivators, social-psychological forces, and organizational climate. MIS Quarterly, 29(1), 87-111.

Bolhuis, S., \& Simons, P. R. J. (2001). Naar een beter begrip van leren [Towards a better understanding of learning]. In J. W. M. Kessels \& R. F. Poell (Eds.), Human resource development: Organiseren van leren (pp. 37-39). Alphen a/d Rijn, The Netherlands: Samsom.

Bowen, D. E., \& Ostroff, C. (2004). Understanding HRM-firm performance linkages: The role of the "strength" of the HRM system. Academy of Management Review, 29, 203-221.

Bryson, J., Pajo, K., Ward, R., \& Mallon, M. (2006). Learning at work: organisational affordances and individual engagement. Journal of workplace learning, 18(5), 279-297.

Carmeli, A., Tishler, A., \& Edmondson, A. C. (2012). CEO relational leadership and strategic decision quality in top management teams: The role of team trust and learning from failure. Strategic Organization, 10, 31-54.
Carr, J. Z., Schmidt, A. M., Ford, J. K., \& DeShon, R. P. (2003). Climate perceptions matter: A meta-analytic path analysis relating molar climate, cognitive and affective states, and individual level work outcomes. Journal of Applied Psychology, 88(4), 605-619.

Cheetham, G., \& Chivers, G. (2001). How professionals learn in practice: an investigation of informal learning amongst people working in professions. Journal of European Industrial Training, 25(5), 247-292.

Chen, C. J., \& Lin B. W. (2004). The effects of environment, knowledge attribute, organizational climate, and firm characteristics on knowledge sourcing decisions. Research and Development Management, 34, 137-146.

Chillarege, K. A., Nordstrom, C. R., \& Williams, K. B. (2003). Learning from our mistakes: error management training for mature learners. Journal of Business and Psychology, 17, 369.

Chughtai, A. A., \& Buckley, F. (2011). Work engagement antecedents, the mediating role of learning goal orientation and job performance. Career Development International, 16(6-7), 684-705.

Cohen, J. (1988). Statistical power analysis for the behavioral sciences. Hillsdale, NJ: Lawrence Erlbaum Associates.

Cramer, J. M. (2003). Learning about corporate social responsibility: The Dutch experience. Amsterdam, The Netherlands: IOS Press.

Delamare Le Deist, F., \& Winterton, J. (2005). What is competence? Human Resource Development International, 8(1), 27-46.

Dentoni, D., Hopes, O., \& Ross, B. (2012). Managing wicked problems in agribusiness: the role of multi-stakeholder engagements in value creation. International Food and Agribusiness Management Review, 15(special issue B), 1-12.

Dragoni, L., Tesluk, P. E., Russell, J. E. A., \& Oh, I. (2009). Understanding managerial development: Integrating developmental assignments, learning orientation, and access to developmental opportunities in predicting managerial competencies. The Academy of Management, 52(4), 731-743.

Dweck, C. S., \& Leggett, E. L. (1988). A social-cognitive approach to motivation and personality. Psychological Review, 95, 256-273.

Edmondson, A. C. (2004). Learning from mistakes is easier said than done: Group and organizational influences on the detection and correction of human error. The Journal of Applied Behavioral Science, 40(1), 66-90.

Engeström, Y., \& Middleton, D. (1996). Introduction: studying work as mindful practice. In Y. Engeström \& D. Middleton (Eds.), Cognition and communication at work (pp. 1-15). Cambridge, UK: Cambridge University Press.

Fuller, A., \& Unwin, L. (2004). Expansive learning environments. Integrating organizational and personal development. In $\mathrm{H}$. 
Rainbird, A. Fuller, \& A. Munro (Eds.), Workplace learning in context (pp. 126-144). London, UK: Routledge.

Fuller, A., Hodkinson, H., Hodkinson, P., \& Unwin, L. (2005). Learning as peripheral participation in communities of practice: A reassessment of key concepts in workplace learning. British Educational Research Journal, 31(1), 49-68.

Furst, S. A., \& Cable, D. M. (2008). Employees resistance to organizational change: Managerial influence tactics and leadermember exchange. Journal of Applied Psychology, 93(2), 453-462.

Gronewold, U., Gold, A., \& Salterio, S. E. (2013). Reporting selfmade errors: The impact of organizational error-management climate and error type. Journal of Business Ethics, 117, 189-208.

Grossman, R., \& Salas, E. (2011). The transfer of training: What really matters. International Journal of Training and Development, $15,103-120$.

Gulikers, J. T. M. (2006). Authenticity is in the eye of the beholder: Beliefs and perceptions of authentic assessment and the impact on student learning. Unpublished doctoral dissertation, Open University, Maastricht, The Netherlands.

Heiskanen, E., Thidell, A., \& Rodhe, H. (2015). Educating sustainability change agents: The importance of practical skills and experience. Journal of Cleaner Production, 123, 218-226.

Hodkinson, P. H., \& Hodkinson, H. (2004). The significance of individuals' dispositions in the workplace learning: A case study of two teachers. Journal of Education and Work, 17(2), 167-182.

Hu, L. T., \& Bentler, P. M. (1999). Cutoff criteria for fit indexes in covariance structure analysis: Conventional criteria versus new alternatives. Structural Equation Modeling: A Multidisciplinary Journal, 6, 1-55.

Huang, S. K. (2013). The impact of CEO characteristics on corporate sustainable development. Corporate Social Responsibility and Environmental Management, 20, 234-244.

Hutjens, A., Dentchev, N. A., \& Haezendonck, E. (2015). CSR implementation in Belgium: Institutional context, the role of CSR managers and stakeholder involvement. In S. Idowu, R. Schmidpeter, \& M. Fifka (Eds.), Corporate Social Responsibility in Europe. United in Sustainable Diversity. Switzerland: Springer.

Illeris, K. (2011). The fundamentals of workplace learning. Understanding how people learn in working life. NY: Routeledge.

Jamali, D. (2008). A stakeholder approach to corporate social responsibility: A fresh perspective into theory and practice. Journal of Business Ethics, 82(1), 213-231.

James, L. R., Choi, C. C., Ko, C. H. E., McNeil, P. K., Minton, M. K., et al. (2008). Organizational and psychological climate: A review of theory and research. European Journal of Work and Organizational Psychology, 17, 5-32.

Klarus, R. (2011). Ervaring is een vak, werken is leren [Experience is a trade, work is learing]. In J. W. M. Kessels \& R. Poell (Eds.), Handboek human resource development. Organiseren van het leren (pp. 87-103). Houten, The Netherlands: Bohn, Stafleu, van Loghum.

Kyndt, E., \& Baert, H. (2013). Antecedents of employees' involvement in work-related learning: A systematic review. Review of Educational Research, 83(2), 273-313.

Kyndt, E., Dochy, F., Michielsen, M., \& Moeyaert, B. (2009). Employee retention: Organisational and personal perspectives. Vocations and Learning, 2, 195-215.

Lawson, B., Petersen, K. J., Cousins, P. D., \& Handfield, R. B. (2009). Knowledge sharing in interorganizational product development teams: the effect of formal and informal socialization mechanisms. The Journal of Product Innovation Management, 26, 156-172.

Marsick, V. J., \& Watkins, K. E. (2003). Demonstrating the value of an organization's learning culture: The dimensions of the learning organization questionnaire. Advances in Developing Human Resources, 5, 132-151.

Mazutis, D. D. (2013). The CEO effect: A longitudinal, multilevel analysis of the relationship between executive orientation and corporate social strategy. Business and Society, 52(4), 631-648.

Meyer, R. D., \& Dalal, R. S. (2009). Situational strength as a means of conceptualizing context. Industrial and Organizational Psychology: Perspectives on Science and Practice, 2, 99-102.

Mulder, M. (2014). Conceptions of professional competence. In S. Billett, C. Harteis, \& H. Gruber (Eds.), International handbook on research into professional and practice-based learning (pp. 107-137). Dordrecht, The Netherlands: Springer.

Nikolova, I., Van Ruysseveldt, J., De Witte, H., \& Syroit, J. (2014a) Work-based learning: Development and validation of a scale measuring the learning potential of the workplace (LPW). Journal of Vocational Behavior, 84(1), 1-10.

Nikolova, I., Van Ruysseveldt, J., De Witte, H., \& Van Dam, K. (2014b). Learning climate scale: Construction, reliability and initial validity evidence. Journal of Vocational Behavior, 85, 258-265.

Nijhof, A., De Bruijn, T., Fisscher, O., Jonker, J., Karssing, E., \& Schoemaker, M. (2005). Learning to be responsible: Developing competencies for organisation wide CSR. In J. Jonker \& J. Cramer (Eds.), Making a difference: The Dutch national program on corporate social responsibility (pp. 57-84). The Hague, The Netherlands: Ministry of Economic Affairs.

Noordzij, G., Van Hooft, E. A. J., Van Mierlo, H., Van Dam, A., \& Born, A. P. (2013). The effects of a learning goal orientation training on self-regulation: Afield experiment among unemployed job seekers. Personell Psychology, 66(3), 723-755.

O'Connor, B. P. (2000). SPSS and SAS programs for determining the number of components using parallel analysis and Velicer's MAP test. Behavior Research Methods, Instruments, and Computers, 32(3), 396-402.

Osagie, E. R., Wesselink, R., Blok, V., Lans, T., \& Mulder, M. (2016a). Individual competencies for corporate social responsibility: A literature and practice perspective. Journal of Business Ethics, 135, 233-252.

Osagie, E. R., Wesselink, R., Blok, V., \& Mulder, M. (2016b). Contextualizing individual competencies for managing the corporate social responsibility adaptation process: The apparent influence of the business case logic. Business and Society. doi:10.1177/0007650316676270.

Parker, S. K., \& Collins, C. G. (2010). Taking stock: Integrating and differentiating multiple proactive behaviors. Journal of Management, 36(3), 633-662.

Payne, S. C., Youngcourt, S. S., \& Beaubien, J. M. (2007). A metaanalytic examination of the goal orientation nomological net. Journal of Applied Psychology, 92, 128-150.

Podsakoff, P. M., MacKenzie, S. B., Lee, J. Y., \& Podsakoff, N. P. (2003). Common method biases in behavioral research: A critical review of the literature and recommended remedies. Journal of Applied Psychology, 88(5), 879-903.

Poell, R. F., Chivers, G. E., van der Krogt, F. J., \& Wildemeersch, D. A. (2000). Learning network theory: Organizing the dynamic relationships between learning and work. Management Learning, 31(1), 25-49.

Rieckmann, M. (2012). Future-oriented higher education: Which key competencies should be fostered through university teaching and learning? Futures, 44, 127-135.

Runhaar, P., Sanders, K., \& Haudong, Y. (2010). Stimulating teachers' reflection and feedback asking: An interplay of selfefficacy, learning goal orientation, and transformational leadership. Teaching and Teacher Education, 26, 1154-1161.

Schneider, B., Ehrhart, M. G., \& Macey, W. H. (2013). Organizational climate and culture. Annual Review of Psychology, 64, 361-388. 
Spector, P. E. (2006). Method variance in organizational research: Truth or urban legend. Organizational Research Methods, 9, 221-232.

Sujan, H., Weitz, B. A., \& Kumar, N. (1994). Learning orientation, working smart and effective selling. Journal of Marketing, 58(3), $39-52$.

Tracey, J. B., \& Tews, M. J. (2005). Construct validity of a general training climate scale. Organizational Research Methods, 8, 353-374.

Tynjälä, P. (2008). Perspectives into learning at the workplace. Educational Research Review, 3, 130-154.

Van der Krogt, F. J. (1995). Leren in netwerken [Learning in networks]. Utrecht, The Netherlands: Lemma.

Van der Krogt, F. J. (1998). Learning network theory: The tension between learning systems and work systems in organizations. Human Resource Development Quarterly, 9(2), 157-177.

VandeWalle, D. (1997). Development and validation of a work domain goal orientation instrument. Educational and Psychological Measurement, 57, 995-1015.

VandeWalle, D. (2001). The role of goal orientation following performance feedback. Journal of Applied Psychology, 86(4), 629-640.
Vera-Cruz, A. O. (2006). Firms' culture and technological behaviour: The case of two breweries in Mexico. International Journal of Technology Management, 36(1-3), 148-165.

Waldman, D. A., Siegel, D. S., \& Javidan, M. (2006). Components of CEO transformational leadership and corporate social responsibility. Journal of Management Studies, 43(8), 1703-1725.

Wiek, A., Withycombe, L., \& Redman, C. L. (2011). Key competencies in sustainability: A reference framework for academic program development. Sustainability Science, 6, 203-218.

Wijdoogen, C. (2016). MVO doe je zo: Het vak van duurzaamheidsmanager vanuit mijn ervaring bij NS (CSR, here is how to do it: The profession of sustainability manager from my experience at the NS [Dutch Railways].). Den Haag, The Netherlands: Maurits Groen Milieu \& Communicatie.

Willard, M., Wiedmeyer, C., Warren Flint, R., Weedon, J. S., Woodward, R., Feldman, I., et al. (2010). The sustainability professional: 2010 competency survey report. Environmental Quality Management, 20(1, Autumn), 49-83.

Withagen, R., De Poel, H. J., Araújo, D., \& Peppeing, G. (2012). Affordances can invite behavior: Reconsidering the relationship between affordances and agency. New Ideas in Psychology, 30, $250-258$. 